\title{
TGF $\beta$ receptor gene variants in systemic sclerosis-related pulmonary arterial hypertension: results from a multicentre EUSTAR study of European Caucasian patients
}

\author{
Eugénie Koumakis, ${ }^{1,2}$ Julien Wipff, ${ }^{1,2}$ Philippe Dieudé, ${ }^{3}$ Barbara Ruiz, ${ }^{1}$ \\ Matthieu Bouaziz, ${ }^{4}$ Lucile Revillod, ${ }^{1}$ Mickaël Guedj, ${ }^{4}$ Jörg H W Distler, ${ }^{5}$ \\ Marco Matucci-Cerinic, ${ }^{6}$ Marc Humbert, ${ }^{7-9}$ Gabriella Riemekasten, ${ }^{10,11}$ Paolo Airo, ${ }^{12}$ \\ Inga Melchers, ${ }^{13}$ Eric Hachulla, ${ }^{14}$ Daniele Cusi, ${ }^{15,16}$ H- Erich Wichmann, ${ }^{17,18,19}$ \\ Nicolas Hunzelmann, ${ }^{20}$ Kiet Tiev, $^{21}$ Paola Caramaschi, ${ }^{22}$ Elisabeth Diot, ${ }^{23}$

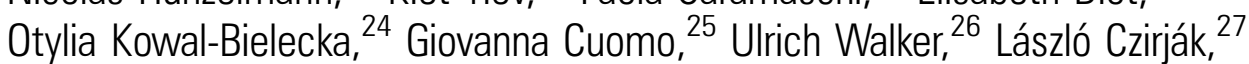 \\ Nemanja Damjanov, ${ }^{28}$ Sara Lupoli, ${ }^{16}$ Costanza Conti, ${ }^{29}$ Martina Müller-Nurasyid, ${ }^{30,31,32}$ \\ Ulf Müller-Ladner, ${ }^{33}$ Valeria Riccieri, ${ }^{34}$ Jean-Luc Cracowski, ${ }^{35}$ Franco Cozzi, ${ }^{36}$ \\ Vasiliki Kalliopi Bournia, ${ }^{37}$ P Vlachoyiannopoulos, ${ }^{37}$ Gilles Chiocchia, ${ }^{1}$ \\ Catherine Boileau, ${ }^{38}$ Yannick Allanore ${ }^{1,2}$
}

For numbered affiliations see end of article.

\section{Correspondence to} Professor Yannick Allanore, Service de Rhumatologie A, Hôpital Cochin, 27 rue du Faubourg Saint-Jacques, Paris 75014, France; yannick.allanore@cch.aphp.fr

Accepted 18 July 2012 Published Online First 15 August 2012

\section{ABSTRACT}

Introduction Systemic sclerosis (SSc)-related pulmonary arterial hypertension (PAH) has emerged as a major mortality prognostic factor. Mutations of transforming growth factor beta (TGF $\beta$ ) receptor genes strongly contribute to idiopathic and familial PAH.

Objective To explore the genetic bases of SSc-PAH, we combined direct sequencing and genotyping of candidate genes encoding TGF $\beta$ receptor family members.

Materials and methods TGF $\beta$ receptor genes, BMPR2, ALK1, TGFR2 and ENG, were sequenced in 10 SSc-PAH patients, nine SSc and seven controls. In addition, 22 single-nucleotide polymorphisms (SNP) of these four candidate genes were tested for association in a first set of 824 French Caucasian SSc patients (including 54 SSc-PAH) and 939 controls. The replication set consisted of 1516 European SSc (including 219 SSc$\mathrm{PAH})$ and 3129 controls from the European League Against Rheumatism Scleroderma Trials and Research group network.

Results No mutation was identified by direct sequencing. However, two repertoried SNP, ENG rs35400405 and ALK1 rs2277382, were found in SSc-PAH patients only. The genotyping of 22 SNP including the latter showed that only rs2277382 was associated with SSc-PAH ( $p=0.0066,0 R 2.13,95 \% \mathrm{Cl}$ 1.24 to 3.65$)$. Nevertheless, this was not replicated with the following result in combined analysis: $p=0.123,0 R$ $0.79,95 \% \mathrm{Cl} 0.59$ to 1.07 .

Conclusions This study demonstrates the lack of association between these TGF $\beta$ receptor gene polymorphisms and SSc-PAH using both sequencing and genotyping methods.

\section{INTRODUCTION}

Systemic sclerosis (SSc) is characterised by major vascular involvement. Pulmonary arterial hypertension (PAH) is currently an important challenge in SSc and given the severity of this condition and the poor understanding of its risk factors and pathogenesis, there is an urgent need to identify novel risk factors for the development of SSc-PAH. ${ }^{1}$ The identification of mutations in the BMPR2 gene, and also in other transforming growth factor beta (TGF $\beta$ ) receptor genes in idiopathic $\mathrm{PAH}$ and familial $\mathrm{PAH}$ has been an important step forward. Indeed, mutations in the BMPR2 gene, which encodes a type II bone morphogenetic protein receptor of the TGF $\beta$ cell signalling superfamily, underlie the majority of hereditary PAH cases ${ }^{2}$ but have also been identified in other disease subtypes including idiopathic $\mathrm{PAH}$ and PAH associated with other disorders. ${ }^{3} 4$ Mutations in two further receptor members of the TGF $\beta$ signalling superfamily have been identified as uncommon causes of hereditary PAH. Indeed, hereditary haemorrhagic telangiectasia (HHT) is an autosomal dominant vascular disease, caused by heterozygous mutations of either TGF $\beta$ type I receptor activin-like kinase-type 1 ( $A L K 1)$ or of the endoglin gene $(E N G) .{ }^{5} \mathrm{~A}$ small proportion of HHT patients have PAH that is clinically and histopathologically indistinguishable from other heritable forms of PAH. In rare cases, mutations of $A L K-1$ appeared to cause idiopathic $\mathrm{PAH}$ and hereditary PAH without HHT. ${ }^{4}$ Therefore, BMPR2, ALK1 and $E N G$ genes, belonging to the TGF $\beta$ superfamily, represent good candidates for the study of genetic susceptibility to SSc-PAH.

Few studies have attempted to identify SSc-PAH genetic risk factors. Despite some relevant prelimin- 
ary results, a lack of appropriate cohorts (because of imperfect phenotype and/or insufficient statistical power) has precluded definite conclusions. ${ }^{6-9}$

The aim of this study was to investigate a specific genetic basis favouring the occurrence of PAH in SSc, using a synergistic strategy combining direct sequencing together with genotyping of common variants of candidate genes encoding four TGF $\beta$ receptors: $B M P R 2, A L K 1, E N G$ and TGFBR2.

\section{PATIENTS AND METHODS \\ Study population}

All SSc patients and controls were of European Caucasian origin and were provided through the European League Against Rheumatism Scleroderma Trials and Research group (EUSTAR) centres. The discovery set consisted of 824 SSc patients, including $54 \mathrm{SSc}-\mathrm{PAH}$ patients and 939 controls from French centres. The replication set consisted of cohorts from other French centres (175 SSc patients including 75 SSc-PAH patients and 438 controls), northern/central Europe (455 SSc, 59 SSc-PAH and 1823 controls), Italy (542 SSc, 33 PAH-SSc and 479 controls) and eastern Europe (344 SSc, 52 SSc-PAH and 389 controls). The characteristics of the study population have been detailed previously. ${ }^{10}$ Clinical data collected included age, sex, disease duration and cutaneous SSc subtypes according to the definition of Leroy et al. ${ }^{11}$ Precapillary PAH diagnosis was established following right heart catheterisation as recommended. ${ }^{12}$ All local institutional review boards approved the study, and written informed consent was obtained from all study subjects.

\section{Direct sequencing}

As a first approach, 26 French Caucasian individuals (10 SSc-PAH patients, nine SSc patients without PAH and seven healthy controls) were sequenced for the candidate genes encoding four TGF $\beta$ receptors: BMPR2, ENG, ALK1 and TGFBR2. Genomic DNA was extracted from blood samples (Qiagen, Courtaboeuf, France). PCR primers were designed using Primer 3 to amplify segments of genomic DNA that included the exons and intronexon boundaries to detect splice-site variants. PCR products were purified using ExoSAP-IT (USB Corp., Cleveland, Ohio, USA) and sequenced using the BigDye Terminator V.3.1 cycle sequencing kit (Applied Biosystems, Foster City, California, USA).

\section{Genotyping}

As a second approach, any single-nucleotide variation detected by direct sequencing in SSc-PAH patients and not present either in controls or PAH-free SSc patients, was tested for association in the genotyping cohort. In addition, Tag singlenucleotide polymorphisms (SNP) with a minor allele frequency (MAF) greater than $5 \%$ were genotyped for each of the four TGF $\beta$ receptor genes using the KASpar genotyping system (KBioscience, Hoddesdon, UK) as previously described. ${ }^{13}$ Six SNP of the BMPR2 gene (rs7600694, rs1061157, rs1048829, rs6747756, rs1980153, rs16839127), seven SNP of the TGFBR2 gene (rs377626, rs1841528, rs2372092, rs3773661, rs9867701, rs11466531, rs11466536), four SNP of the ALK1 gene (rs706815, rs772003, rs2277382, rs3782479) and five SNP of the ENG gene (rs35400405, rs1998923, rs1330684, rs10987746, rs17557600) were chosen according to linkage disequilibrium structure. The average genotype completeness for these variants was above $97 \%$ for both the SSc and the control samples.

\section{Statistical analyses}

Statistical analyses were performed as previously described. ${ }^{13}$ The Bonferroni correction was applied for all tests performed for SNP marker association with the disease ( $p$ value multiplied by $\mathrm{n}$ SNP). The analysis of combined data was performed by calculation of the pooled OR under a fixed-effects model (Mantel-Haenszel meta-analysis). No power calculation can be provided for mutation investigations, but regarding common SNP (MAF >5\%) and for ALK1 rs2277382 in particular, the combined sample provides a power of $99.9 \%$ to detect an association with SSc and of $52.3 \%$ for the SSc-PAH subset, with an OR of 1.5 .

\section{RESULTS \\ Sequencing of TGF $\beta R$ genes in cases and controls}

No mutation was identified through the sequencing of 38 SSc and 14 control chromosomes (table 1). We identified 17 polymorphisms: 13 SNP listed in public databases and four variants not yet repertoried, none of which were mutations as they were found both in patients and controls. Two variants emerged as interesting candidates for further study. Indeed, the SNP located at codon 14 of exon 1 in the ENG gene, known as

Table 1 Variants identified by direct sequencing of the ENG, ALK1, TGBR2 and BMPR2 genes

\begin{tabular}{|c|c|c|c|c|c|c|c|c|}
\hline Gene & Location & Nucleotide change & Amino acid change & rs number & MAF & SSc-PAH $(n=10)$ & SSc without PAH $(n=9)$ & Controls $(n=7)$ \\
\hline \multirow[t]{8}{*}{ ENG } & Exon 1 & c. $14 \mathrm{G}>\mathrm{A}$ & \multirow[t]{2}{*}{ p.T5M } & rs35400405 & NA & 3 & 0 & 0 \\
\hline & Intron $1(-215)$ & $\mathrm{T}>\mathrm{C}$ & & rs60683420 & NA & 0 & 2 & 0 \\
\hline & Exon 2 & c.227 C > T & \multirow[t]{4}{*}{ p.L69L } & rs16930129 & 0.165 & 2 & 4 & 2 \\
\hline & Intron 2 (+25) & $A>C$ & & rs7847860 & NA & 0 & 0 & 2 \\
\hline & Intron $5^{*}(+59)$ & del G & & NA & NA & 1 & 1 & 1 \\
\hline & Intron $7^{*}(+23)$ & ins TССССС & & NA & NA & 1 & 9 & 4 \\
\hline & Exon 8 & c. $1029 \mathrm{G}>\mathrm{A}$ & \multirow[t]{6}{*}{ p.H343H } & rs3739817 & 0.066 & 0 & 5 & 4 \\
\hline & Intron $13(-72)$ & $A>G$ & & rs10760503 & 0.407 & 3 & 6 & 2 \\
\hline \multirow[t]{4}{*}{$A L K 1$} & Promoter $(-38)$ & $\mathrm{C}>\mathrm{T}$ & & rs2277382 & 0.075 & 3 & 0 & 0 \\
\hline & Intron $3(+11)$ & $\mathrm{T}>\mathrm{C}$ & & rs2071218 & NA & 7 & 4 & 5 \\
\hline & Intron $3(-36)^{*}$ & $\mathrm{~T}>\mathrm{A}$ & & NA & NA & 6 & 5 & 4 \\
\hline & Intron $5(+44)^{*}$ & $A>G$ & & NA & NA & 0 & 0 & 4 \\
\hline \multirow[t]{3}{*}{ TGFBR2 } & Intron $2(+7)$ & $A>G$ & \multirow[t]{3}{*}{ p.N389N } & rs1155705 & 0.336 & 4 & 5 & 3 \\
\hline & Intron $3(-4)$ & $\mathrm{A}>\mathrm{T}$ & & rs11466512 & NA & 8 & 4 & 4 \\
\hline & Exon 4 & c. $1167 \mathrm{C}>\mathrm{T}$ & & rs2228048 & 0.027 & 0 & 0 & 1 \\
\hline \multirow[t]{2}{*}{ BMPR2 } & Intron $6(-22)$ & $\operatorname{del} \mathrm{T}$ & \multirow[t]{2}{*}{ p.R937R } & rs11464745 & NA & 1 & 2 & 0 \\
\hline & Exon 12 & c. $2811 \mathrm{G}>\mathrm{A}$ & & rs1061157 & 0.128 & 3 & 2 & 3 \\
\hline
\end{tabular}

${ }^{*}$ Novel variants

$A L K 1$, activin A receptor type II-like 1; BMPR2, BMP receptor type II; ENG, endoglin; MAF, minor allele frequency; NA, not available; PAH, pulmonary arterial hypertension; $\mathrm{SSc}$, systemic sclerosis; TGFBR2, TGFbeta receptor type II. 
rs35400405, introduces an in-frame ATG sequence downstream of the usual initiating codon that might result in the loss of the first amino acids. This variation was detected in SSc-PAH patients only and none of the controls. The rs2277382 SNP of the ALK1 gene was found only in three SSc-PAH patients, none of the PAH-free patients and none of the controls. This SNP is located in the promoter of the gene, and has previously been identified as a single-nucleotide variation associated with $\mathrm{HHT}^{14}$

\section{Association testing of identified variants and common tag SNP of the TGFBR genes}

Discovery set

We investigated the possible association of polymorphisms in the ALK1, TGFBR2, BMPR2 and EGN genes with SSc and the SScPAH subtype by genotyping rs35400405, rs2277382 and 20 tag SNP distributed throughout these genes (table 2). No association was found with SSc in the discovery set. Genetic association was solely observed between the SSc-PAH subset and the ALK1 rs2277382 SNP (OR 2.13, 95\% CI 1.24 to 3.65, padj $=0.0066)$.

\section{Replication set}

Following the results obtained in the discovery set, we selected the ALK1 rs2277382 SNP to be investigated in the EUSTAR replication cohort (table 3 ). Genotype frequencies of the rs2277382 variant were in Hardy-Weinberg equilibrium in all control populations. However, we did not observe any association between the rs2277382T allele and either SSc-PAH or the SSc subset in these replication sets.

\section{Meta-analysis in the European Caucasian population}

Meta-analysis of the combined discovery and replication populations (French, northern European, Italian and eastern European) including a total of 2340 SSc patients, 273 SSc-PAH and 4068 controls did not provide evidence for an association between ALK1 rs2277382 and neither SSc-PAH nor SSc.

\section{DISCUSSION}

Genes encoding TGF $\beta$ receptors have been identified as major susceptibility genes in familial and idiopathic forms of $\mathrm{PAH}$. Understanding the genetic differences between idiopathic $\mathrm{PAH}$ and SSc-PAH, and also between patients with SSc who do and do not develop $\mathrm{PAH}$, may improve our ability to develop genetic biomarkers of SSc-PAH. This may help to identify these patients earlier in the disease course and to risk stratify patients in order to optimise the management of this devastating condition.

So far, preliminary studies investigating BMPR2 and ALK1 have failed to identify variants associated with SSc-PAH by a direct sequencing strategy. However, they were limited by small sample size and heterogeneous definition of $\mathrm{PAH}^{7-9}$
Table 3 Association study of ALK1 rs2277382 with SSc and PAH-SSc in the second set of European Caucasian populations and combined analysis including the discovery and replication cohorts

\begin{tabular}{|c|c|c|c|c|}
\hline & $\mathbf{N}$ & MAF (\%) & p Value & OR (95\% Cl) \\
\hline \multicolumn{5}{|c|}{ French replication cohort } \\
\hline SSc & 175 & 8.57 & 0.410 & $1.21(0.77$ to 1.90$)$ \\
\hline $\mathrm{PAH}-\mathrm{SSC}$ & 75 & 8.67 & 0.524 & 1.23 (0.66 to 2.29 ) \\
\hline Controls & 438 & 7.19 & NA & NA \\
\hline \multicolumn{5}{|l|}{ Italians } \\
\hline SSc & 542 & 8.76 & 0.870 & $1.03(0.75$ to 1.40$)$ \\
\hline $\mathrm{PAH}-\mathrm{SSc}$ & 33 & 9.09 & 0.881 & 1.07 (0.45 to 2.55$)$ \\
\hline Controls & 479 & 8.56 & NA & NA \\
\hline \multicolumn{5}{|c|}{ Northern European } \\
\hline SSc & 455 & 8.46 & 0.990 & $0.10(0.77$ to 1.30$)$ \\
\hline PAH-SSc & 59 & 11.02 & 0.331 & 1.34 (0.74 to 2.41$)$ \\
\hline Controls & 1823 & 8.48 & NA & NA \\
\hline \multicolumn{5}{|c|}{ Eastern European } \\
\hline SSc & 344 & 5.96 & 0.570 & 0.89 (0.58 to 1.35$)$ \\
\hline PAH-SSc & 52 & 2.88 & 0.132 & 0.42 (0.13 to 1.35$)$ \\
\hline Controls & 389 & 6.68 & NA & NA \\
\hline
\end{tabular}

Meta-analysis in the combined discovery and replication populations in an additive model

$\begin{array}{lllll}\text { SSc } & 2340 & 8.44 & 0.149 & 0.91(0.80 \text { to } 1.04) \\ \text { PAH-SSc } & 273 & 9.52 & 0.123 & 0.79(0.59 \text { to } 1.07) \\ \text { Controls } & 4068 & 7.72 & \text { NA } & \text { NA }\end{array}$

Northern European: Germany and Poland; Eastern European: Greece, Hungary, Romania, Serbia.

MAF, minor allele frequency; NA, not applicable; PAH, pulmonary arterial hypertension; SSc, systemic sclerosis.

Furthermore, an insertion in intron 7 of the ENG gene (6bINS) was reported to be negatively associated with the occurrence of SSc-PAH in a previous work from our group in a small cohort of 280 SSc patients including 29 with PAH and 140 controls. $^{15}$ However, until now this result has not been replicated in a larger cohort.

In this study, the ALK1 rs2277382 and ENG rs35400405 SNP were of particular interest because they were detected only in SSc-PAH patients by direct sequencing, the hypothesis being that their minor alleles could be associated with the development of PAH in our cohorts. However, no association was found between these polymorphisms and both the complication that is SSc-PAH and also SSc. This does not rule out the possible implication of other TGF $\beta$ signalling pathway genes. Indeed, mutations in the $S M A D$ genes have recently been identified in PAH patients and could represent another potential candidate to take into account in the genetics of SSc-PAH in further studies. ${ }^{16}$ Furthermore, another limitation may come from the fact that some SSc patients may develop PAH later during the course of the disease.

Table 2 Association study of $A L K 1$ rs2277382 and ENG rs35400405 SNP in the French discovery cohort

\begin{tabular}{|c|c|c|c|c|c|c|}
\hline & & $\mathbf{N}$ & MAF (\%) & Fischer's p value & p-adj* & OR (95\% Cl) \\
\hline \multirow[t]{3}{*}{$A L K 1 \mathrm{rs} 2277382$} & SSc & 824 & 9.04 & 0.003 & 0.066 & $1.43(1.13$ to 1.81$)$ \\
\hline & $\mathrm{PAH}-\mathrm{SSc}$ & 54 & 12.9 & 0.0003 & 0.0066 & $2.13(1.24$ to 3.65$)$ \\
\hline & Controls & 939 & 6.50 & NA & NA & NA \\
\hline \multirow[t]{3}{*}{ ENG rs35400405 } & SSc & 822 & 2.49 & 0.26 & NS & $1.30(0.82$ to 2.05$)$ \\
\hline & $\mathrm{PAH}-\mathrm{SSc}$ & 54 & 3.64 & 0.22 & NS & $1.92(0.67$ to 5.49$)$ \\
\hline & Controls & 906 & 1.93 & NA & NA & NA \\
\hline
\end{tabular}

ENG, endoglin gene; MAF, minor allele frequency; NA, not applicable; $\mathrm{p}$-adj*, adjusted $\mathrm{p}$ value after Bonferroni correction for multiple SNP testing (n=22); PAH, pulmonary arterial hypertension; SNP, single-nucleotide polymorphism; SSc, systemic sclerosis. 
In conclusion, this study was conducted using a synergistic strategy combining direct sequencing for the identification of potential mutations or rare variants, and genotyping of common variants in a large sample including a replication step. These analyses demonstrate the lack of association between these TGF $\beta$ receptor gene polymorphisms and SSc-PAH.

\section{Author affiliations}

${ }^{1}$ Paris Descartes University, INSERM U1016, Institut Cochin, Sorbonne Paris Cité, Paris, France

${ }^{2}$ Rheumatology A Department, Paris Descartes University, Cochin Hospital, APHP, Paris, France

${ }^{3}$ Department of Rhumatologie, Université Paris 7, INSERM U699, Hôpital Bichat, Paris, France

${ }^{4}$ UMR CNRS-8071/INRA-1152, Université d'Evry Val d'Essonne, Evry, France

${ }^{5}$ Department for Internal Medicine 3, Institute for Clinical Immunology FriedrichAlexander-University, Erlangen-Nuremberg, Germany

${ }^{6}$ Department of Biomedicine \& Division of Rheumatology AOUC, Department of Rheumatology AVC, Department of Medicine \& Denothe Centre, University of

Florence, Florence, Italy

${ }^{7}$ Université Paris-Sud, Le Kremlin-Bicêtre, France

${ }^{8}$ AP-HP Hôpital Antoine Béclère, Clamart, France

${ }^{9}$ INSERM U999, Centre Chirurgical Marie-Lannelongue, Le Plessis-Robinson, France

${ }^{10}$ Department of Rheumatology and Clinical Immunology, Charité University Hospital,

Berlin, Germany

${ }^{11}$ German Rheumatism Research Centre, a Leibniz Institute, Berlin, Germany

${ }^{12}$ Department of Rheumatology and Clinical Immunology, Spedali Civili, Brescia, Italy

${ }^{13}$ Department of Clinical Research Unit for Rheumatology, University Medical Center,

Freiburg, Germany

${ }^{14}$ Department of Médecine Interne, Université Lille II, Lille, France

${ }^{15}$ University of Milano, Department of Medicine, Surgery, and Dentistry, San Paolo

School of Medicine, Milan, Italy

${ }^{16}$ Genomics and Bioinformatics Platform, Fondazione Filarete, Milan, Italy

${ }^{17}$ Institute of Epidemiology I, Helmholtz Zentrum München - German Research Center

for Environmental Health, Neuherberg, Germany

${ }^{18}$ Institute of Medical Informatics, Biometry and Epidemiology, Chair of Epidemiology,

Ludwig-Maximilians-Universität, Munich, Germany

${ }^{19}$ Klinikum Grosshadern, Munich, Germany

${ }^{20}$ Department of Dermatology, University of Cologne, Cologne, Germany

${ }^{21}$ Université Pierre et Marie Curie, Service de Médecine Interne, Hôpital Saint

Antoine, Paris, France

${ }^{22}$ Department of Clinical and Experimental Medicine, Rheumatology Unit, University of Verona, Verona, Italy

${ }^{23}$ INSERM U618, IFR 135, CHU Bretonneau, Tours, France

${ }^{24}$ Department of Rheumatology and Internal Medicine, Medical University of

Bialystok, Bialystok, Poland

${ }^{25}$ Department of Clinical and Experimental Medicine, Rheumatology Unit, Second

University of Naples, Naples, Italy

${ }^{26}$ Department of Rheumatology, Basel University, Basel, Switzerland

${ }^{27}$ Department of Immunology and Rheumatology, University of Pécs, Pécs, Hungary

${ }^{28}$ Institute of Rheumatology, School of Medicine, University of Belgrade, Belgrade, Serbia

${ }^{29}$ Kos Genetic SRL, Milan, Italy

${ }^{30}$ Institute of Genetic Epidemiology, Helmholtz Zentrum München - German Research

Center for Environmental Health, Neuherberg, Germany

${ }^{31}$ Institute of Medical Informatics, Biometry and Epidemiology, Chair of Epidemiology and Chair of Genetic Epidemiology, Ludwig-Maximilians-Universität, Munich, Germany

${ }^{32}$ Department of Medicine I, University Hospital Grosshadern, Ludwig-Maximilians-

Universität, Munich, Germany

${ }^{33}$ Department of Rheumatology and Clinical Immunology, University of Giessen,

Kerckhoff-Klinik, Bad Nauheim, Germany

${ }^{34}$ Department of Medical Clinic and Therapy, Division of Rheumatology, University 'Sapienza' of Rome, Rome, Italy

${ }^{35}$ INSERM CIC3, CHU Grenoble, Grenoble, France

${ }^{36}$ Cattedra di Reumatologia, Dip. Medicina Clinica e Sperimentale, Policlinico -

Universita' di Padova, Padua, Italy

${ }^{37}$ Department of Pathophysiology, Medical School, University of Athens, Athens, Greece

${ }^{38}$ Department of Biochemistry, Genetic and Hormonology, Ambroise Paré Hospital, Boulogne and INSERM U698, Bichat Hospital, Paris, France
Acknowledgements The authors thank the European League Against Rheumatism Scleroderma Trials and Research group (EUSTAR) for facilitating the DNA collection and supporting the project, the KORA S4 study and HYPERGENE consortium for providing data, respectively, from German and Italian controls, the French members of the GENESYS Consortium (Patrick Carpentier (Grenoble), Jean Sibilia (Strasbourg), Jean Cabane (Paris), Luc Mouthon (Paris), Camille Frances (Paris), Zahir Amoura (Paris), Anne Cosnes (Créteil)). The authors also thank Dr J Benessiano and Prof B Grandchamp (Centre de Ressources Biologiques, Hôpital Bichat, Etablissement Français du Sang (Paris), for their assistance in setting up the French Caucasian control sample.

Contributors All authors contributed substantially to the conception and design, to the drafting of the article and the final approval of the submitted manuscript.

Funding This study was supported by the Association des Sclérodermiques de France, INSERM, Agence Nationale pour la Recherche (grant R07094KS). YA is the recipient of an investigator-initiated research grant from Pfizer.

Competing interests None.

Patient consent Obtained.

Ethics approval All local institutional review boards approved the study.

Provenance and peer review Not commissioned; externally peer reviewed.

\section{REFERENCES}

1. Steen VD, Medsger TA. Changes in causes of death in systemic sclerosis, 1972-2002. Ann Rheum Dis 2007;66:940-4.

2. Machado RD, Koehler R, Glissmeyer E, et al. Genetic association of the serotonin transporter in pulmonary arterial hypertension. Am J Respir Crit Care Med 2006;173:793-7.

3. Cogan JD, Pauciulo MW, Batchman AP, et al. High frequency of BMPR2 exonic deletions/duplications in familial pulmonary arterial hypertension. Am J Respir Crit Care Med 2006;174:590-8.

4. Machado RD, Eickelberg 0, Elliott CG, et al. Genetics and genomics of pulmonary arterial hypertension. J Am Coll Cardiol 2009;54(Suppl 1):S32-42.

5. Harrison RE, Flanagan JA, Sankelo M, et al. Molecular and functional analysis identifies ALK-1 as the predominant cause of pulmonary hypertension related to hereditary haemorrhagic telangiectasia. J Med Genet 2003;40:865-71.

6. Shah SJ. Genetics of systemic sclerosis-associated pulmonary arterial hypertension: recent progress and current concepts. Curr Rheumatol Rep 2009;11:89-96.

7. Tew MB, Arnett FC, Reveille JD, et al. Mutations of bone morphogenetic protein receptor type II are not found in patients with pulmonary hypertension and underlying connective tissue diseases. Arthritis Rheum 2002;46:2829-30.

8. Morse J, Barst R, Horn E, et al. Pulmonary hypertension in scleroderma spectrum of disease: lack of bone morphogenetic protein receptor 2 mutations. J Rheumatol 2002;29:2379-81.

9. Selva-0'Callaghan A, Balada E, Serrano-Acedo S, et al. Mutations of activin-receptor-like kinase 1 (ALK-1) are not found in patients with pulmonary hypertension and underlying connective tissue disease. Clin Rheumatol 2007; 26:947-9.

10. Allanore $\mathbf{Y}$, Saad M, Dieudé $P$, et al. Genome-wide scan identifies TNIP1, PSORS1C1, and RHOB as novel risk loci for systemic sclerosis. PLoS Genet 2011;7: e1002091.

11. LeRoy EC, Black C, Fleischmajer R, et al. Scleroderma (systemic sclerosis): classification, subsets and pathogenesis [editorial]. J Rheumatol 1988;15:202-5.

12. Meune C, Avouac J, Airò P, et al. Prediction of pulmonary hypertension related to systemic sclerosis by an index based on simple clinical observations. Arthritis Rheum 2011;63:2790-6.

13. Dieudé $\mathbf{P}$, Guedj M, Truchetet ME, et al. Association of the CD226 Ser(307) variant with systemic sclerosis: evidence of a contribution of costimulation pathways in systemic sclerosis pathogenesis. Arthritis Rheum 2011;63:1097-105.

14. Abdalla SA, Letarte M. Hereditary haemorrhagic telangiectasia: current views on genetics and mechanisms of disease. J Med Genet 2006;43:97-110.

15. Wipff J, Kahan A, Hachulla E, et al. Association between an endoglin gene polymorphism and systemic sclerosis-related pulmonary arterial hypertension. Rheumatology 2007;:46:622-5.

16. Nasim MT, Ogo T, Ahmed M, et al. Molecular genetic characterization of SMAD signaling molecules in pulmonary arterial hypertension. Hum Mutat 2011;32:1385-9. 


\section{ARD}

\section{TGF $\beta$ receptor gene variants in systemic sclerosis-related pulmonary arterial hypertension: results from a multicentre EUSTAR study of European Caucasian patients}

Eugénie Koumakis, Julien Wipff, Philippe Dieudé, et al.

Ann Rheum Dis 2012 71: 1900-1903 originally published online August 15,2012

doi: 10.1136/annrheumdis-2012-201755

Updated information and services can be found at:

http://ard.bmj.com/content/71/11/1900.full.html

\section{These include:}

References This article cites 15 articles, 5 of which can be accessed free at: http://ard.bmj.com/content/71/11/1900.full.html\#ref-list-1

Article cited in:

http://ard.bmj.com/content/71/11/1900.full.html\#related-urls

Email alerting Receive free email alerts when new articles cite this article. Sign up in service the box at the top right corner of the online article.

Topic Articles on similar topics can be found in the following collections Collections

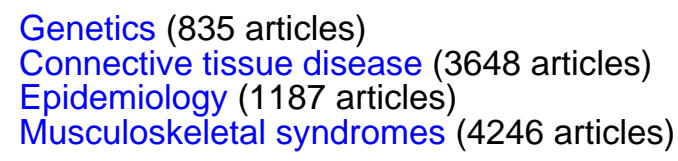

Notes

To request permissions go to:

http://group.bmj.com/group/rights-licensing/permissions

To order reprints go to:

http://journals.bmj.com/cgi/reprintform

To subscribe to BMJ go to:

http://group.bmj.com/subscribe/ 